\title{
Leak-before-break and plastic collapse strength evaluation of stainless steel piping with a part-through notch
}

\author{
Masato OGAWA*, Masaaki MATSUBARA** and Ryosuke SUZUKI** \\ *Graduate School of Science and Technology, Gunma University \\ 1-5-1, Tenjin-cho, Kiryu, Gunma 376-8515, Japan \\ E-mail: t181b015@gunma-u.ac.jp \\ **Graduate School of Science and Technology, Gunma University \\ 1-5-1, Tenjin-cho, Kiryu, Gunma 376-8515, Japan
}

Received: 31 October 2019; Revised: 10 January 2020; Accepted: 4 March 2020

\begin{abstract}
Nuclear power plants and chemical plants contain many piping, which degrades with age. As a result of a reduction in structural strength, guillotine breaking and rupturing can occur, leading to severe damage to plants. Piping is subjected to various types of tension and bending, but the influence of the load history on the integrity of piping containing a flaw is poorly understood. The goal of the present study was to develop an improved integrity assessment method for a stainless steel pipe with a part-through notch that takes into account the load history. This involved first determining the feasibility of the leak-before-break (LBB) concept for piping subjected to a combined load and then evaluating the stress at the crack penetration point and estimating the plastic collapse strength. An austenitic stainless steel pipe (SUS 304) with a length of $110 \mathrm{~mm}$, a diameter of 32 $\mathrm{mm}$, and a wall thickness of $3 \mathrm{~mm}$ was used as a specimen. A part-through notch with a notch angle of $90^{\circ}$ was cut in the center of the specimen by wire electric discharge machining. Loading tests were carried out using statically indeterminate fracture mechanics testing equipment developed by ourselves. This allowed the loading history to be varied because the equipment is capable of applying arbitrary sequences of tension and bending. The LBB concept is considered to be applicable if the crack penetrates before reaching the maximum stress. The plastic collapse strength was then determined using the double elastic slope method. The LBB concept was found to be applicable. In addition, the stress at the crack penetration point was approximately equal to the maximum stress. The results of the present study indicated that the plastic collapse strength of a part-through notched specimen can be safely estimated using the theoretical plastic collapse strength of a through-wall notched pipe.
\end{abstract}

Keywords : Stainless steel pipe, Integrity assessment, Leak-before-break, Plastic collapse strength, DES method

\section{Introduction}

Piping is widely used in fields related to energy storage, such as nuclear power plants. There are several types of nuclear reactors (Suzuki et al., 2016), and many of the nuclear power plants in Japan are light-water reactors. Steam is generated by a light-water reactor using low-enriched uranium as fuel and turns a turbine to create electricity. Piping for transporting steam to the turbine and for transporting cooling water is generally constructed from an austenitic stainless steel, which has excellent ductility, toughness, and corrosion resistance. High-temperature and high-pressure fluid flows in the piping, which is always subjected to tensile stress in the axial direction and the circumferential direction due to the internal pressure (Izawa and Matsubara, 2007a) (Okamura et al., 1975). Damage such as fatigue cracking, thinning, and stress corrosion cracking is caused by aging. In addition, cracks leading to failure occur in the piping when the piping is accidentally subjected to the high stresses caused by earthquakes. The load history of the tension caused by the internal pressure and the bending load due to the earthquake is not clear in actual piping (Izawa et al., 2004) (Izawa et al., 2007b). Therefore, it is necessary to investigate the influence of the load history on the integrity of piping. The integrity 
assessment is carried out based on the Rules on Fitness-for-Service for Nuclear Power Plants (maintenance standard) of the Japan Society of Mechanical Engineers in Japan (JSME, 2008). If flaws are found in the piping at a nuclear power plant, they are modeled in a form that enables the integrity of the piping to be evaluated using fracture mechanics. Then, whether the model of the flaw is within the allowable size range is judged.

The LBB concept is a fail-safe design criterion and is especially important for the nuclear industry (JSME, 2002). In the LBB concept, a significant crack can be detected before a guillotine break because fluid leaks through the crack from piping before unstable fracture occurs. A guillotine break in piping can cause severe damage to a nuclear power plants. The validity of the LBB concept considering the load history has not been sufficiently discussed. The present study attempts to clarify the influence of load history on the validity of LBB for cracked austenitic stainless steel pipe subjected to a combined load of tension and bending, and the following topics are investigated. A combined load of tension and bending is applied to pressurized austenitic stainless steel piping having a part-through notch until failure, and the plastic collapse stress, the stress at the leakage, and the maximum stress are discussed.

\section{Theory}

The theoretical plastic collapse stress is calculated for a pipe with a circumferential part-through notch. The distribution of the stress along the axial direction in the ligament area of a part-through notched pipe subjected to a combined axial force $F$ and bending moment $M$ at plastic collapse is shown in Fig. 1.

The pipe is assumed to be a thin-walled cylinder and an elastic-perfectly plastic body to calculate the theoretical plastic collapse stress. The relationship between the membrane stress, $\sigma_{\mathrm{m}}$, and the bending stress, $\sigma_{\mathrm{b}}$, for the part-thorough notched pipe at plastic collapse can be obtained from the following equations:

$$
\begin{aligned}
& \frac{\sigma_{\mathrm{b}}}{\sigma_{\mathrm{y}}}=\frac{2 t R_{\mathrm{m}}\left\{2 R_{\mathrm{m}} \sin \beta-R_{\mathrm{m}} \sin \theta+\left|Y_{\mathrm{z}}\right|(\pi-\theta-2 \beta)\right\}}{Z_{\mathrm{e}}}+\frac{\left(R_{3}-R_{2}\right)\left(R_{3}+R_{2}\right)\left(\frac{R_{3}+R_{2}}{2} \sin \theta+\left|Y_{\mathrm{z}}\right| \theta\right)}{Z_{\mathrm{e}}} \\
& \beta=\frac{1}{4 t R_{\mathrm{m}}}\left\{2 t R_{\mathrm{m}}(\pi-\theta)+\left(R_{3}-R_{2}\right)\left(R_{3}+R_{2}\right) \theta\right\}\left(1-\frac{\sigma_{\mathrm{m}}}{\sigma_{\mathrm{y}}}\right) \\
& \frac{\sigma_{\mathrm{m}}}{\sigma_{\mathrm{y}}}=\frac{2 t R_{\mathrm{m}}(\pi-\theta-2 \beta)+\left(R_{3}-R_{2}\right)\left(R_{3}+R_{2}\right) \theta}{2 t R_{\mathrm{m}}(\pi-\theta)+\left(R_{3}-R_{2}\right)\left(R_{3}+R_{2}\right) \theta} \\
& I_{z}=t R_{\mathrm{m}}^{3}\left(\pi-\theta-\frac{1}{2} \sin 2 \theta\right)+\frac{1}{8}\left(R_{3}+R_{2}\right)^{3}\left(R_{3}-R_{2}\right)\left(\theta+\frac{1}{2} \sin 2 \theta\right)- \\
& \left(\frac{-2 t R_{\mathrm{m}}^{2} \sin \theta+\frac{1}{2}\left(R_{3}+R_{2}\right)^{2}\left(R_{3}-R_{2}\right) \sin \theta}{2 t R_{\mathrm{m}}(\pi-\theta)+\left(R_{3}-R_{2}\right)\left(R_{3}+R_{2}\right) \theta}\right)^{2}\left\{2 t R_{\mathrm{m}}(\pi-\theta)+\left(R_{3}-R_{2}\right)\left(R_{3}+R_{2}\right) \theta\right\} \\
& Z_{e}=\frac{I_{z}}{R_{3}+\left|Y_{\mathrm{z}}\right|}
\end{aligned}
$$

where $\theta$ is the half notch angle, $R_{\mathrm{m}}$ is the average radius of the pipe, $R_{1}$ is the outer radius of the pipe, $R_{2}$ is the inner radius of the pipe, $R_{3}$ is the curvature radius of the bottom of notch, $Y_{z}$ is the distance from the center to the centroid of the crosssection of the ligament, $Z_{e}$ is the section modulus in the ligament section, $t$ is the pipe wall thickness, and $\sigma_{\mathrm{y}}$ is the yield stress of the pipe material. The theoretical plastic collapse limit curve of an austenitic stainless steel pipe with a circumferential part-through notch having a notch angle of $90^{\circ}$ is shown in Fig. 2. The theoretical plastic collapse limit curve is used to determine the loading paths for the experiments and to evaluate the experimental plastic collapse stress and maximum stress. 

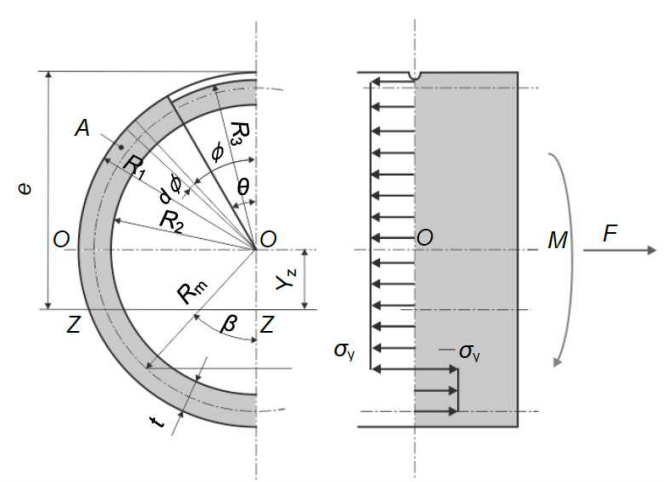

Fig. 1 Stress distribution of piping with a circumferential part-through notch.

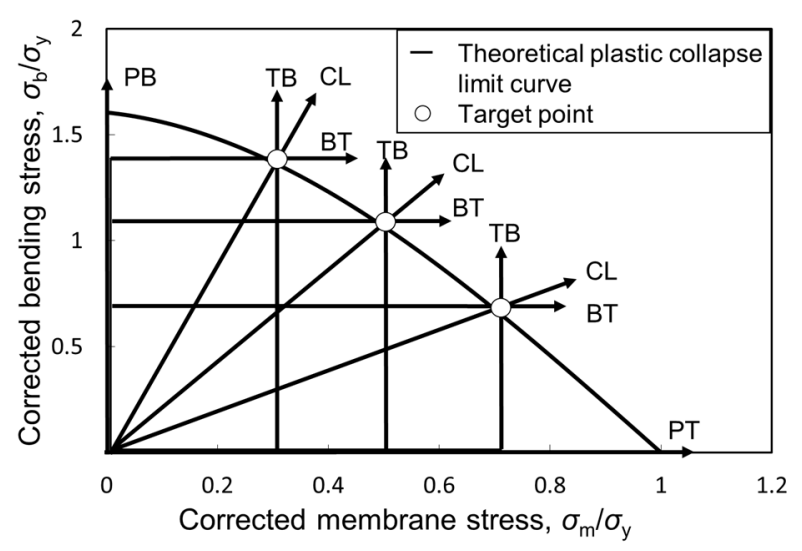

Fig. 2 Loading patterns through the target points for the partthrough notched specimens.

\section{Experimental}

\subsection{Specimen}

An austenitic stainless steel pipe (SUS 304) was used as a specimen. A schematic diagram of the specimens is shown in Fig. 3, and the mechanical properties are listed in Table 1. The specimen has a length of $110 \mathrm{~mm}$, a diameter of 32.0 $\mathrm{mm}$, and a thickness of $3.0 \mathrm{~mm}$. A part-thorough notch with a depth of $1.5 \mathrm{~mm}$ and a notch angle of $90^{\circ}$ was cut into the center of the specimen by wire electric discharge machining. Another type of specimen with a through-wall notch having a notch angle of $90^{\circ}$ was made for comparison. The notch tip radius was $0.16 \mathrm{~mm}$, and the notch width was $0.32 \mathrm{~mm}$. The jigs were welded to both ends of the specimens. A schematic diagram of the specimen with the jigs is shown in Fig. 4. An air valve was attached to a jig, and a pressure gauge was attached the other jig. The part-through notched specimen was subjected to internal air pressure. The internal air pressure in the specimen was measured using a pressure gauge. The internal pressure decreased due to air leaking from the specimen when the crack extended from the notch tip to the inside of the pipe wall. The stress at the crack penetration point can be obtained as the stress at the air-leakage point.

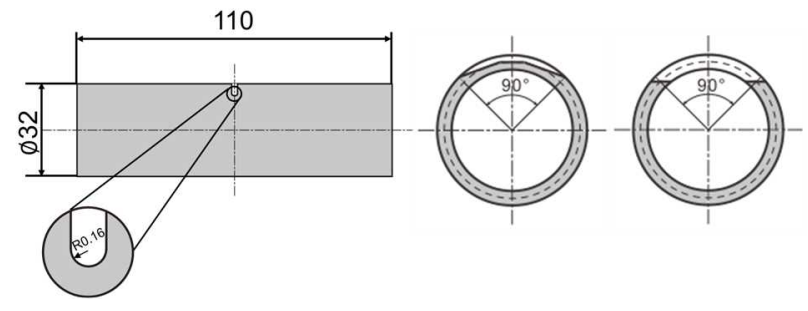

Fig. 3 A part-through notched specimen and a through-wall notched specimen.

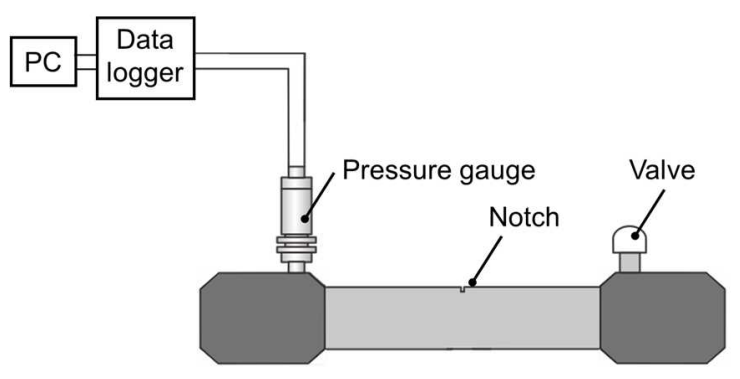

Fig. 4 Specimen setup. 
Table 1 Mechanical properties of the pipe material.

\begin{tabular}{cc}
\hline $\begin{array}{c}\text { Yield stress } \\
\sigma_{\mathrm{y}} / \mathrm{MPa}\end{array}$ & $\begin{array}{c}\text { Ultimate tensile strength } \\
\sigma_{\mathrm{u}} / \mathrm{MPa}\end{array}$ \\
\hline 262 & 606 \\
\hline
\end{tabular}

\subsection{Testing Equipment}

Loading tests were carried out using statically indeterminate fracture mechanics testing equipment developed by our university (Matsubara et al., 2003). A photograph and schematic diagram of the testing equipment are shown in Figs. 5 and 6, respectively. A load cell, a displacement gauge, and an actuator are installed in both the axial direction and the vertical direction in the testing equipment. The deflection angle is measured with two displacement gauges on top of the specimen. The testing equipment can apply arbitrary sequences of tension and bending to the specimen. The loading test can be carried out considering the load history by using this testing equipment.

Both ends of the specimen are attached to the horizontal actuator and a horizontal load cell via the jig. A bending moment is applied to the specimen by four-point bending. The distances between the inner supports and between the outer supports are $70 \mathrm{~mm}$ and $384 \mathrm{~mm}$, respectively. A roller is installed the tip of inner support in order to prevent the influence of a frictional force caused by the friction between the specimen and the inner supports during the loading test.

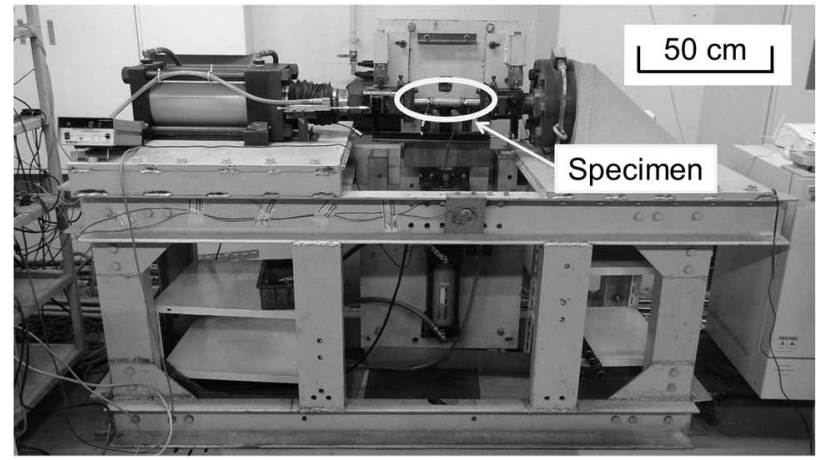

Fig. 5 Photograph of the testing equipment for statically indeterminate fracture mechanics.

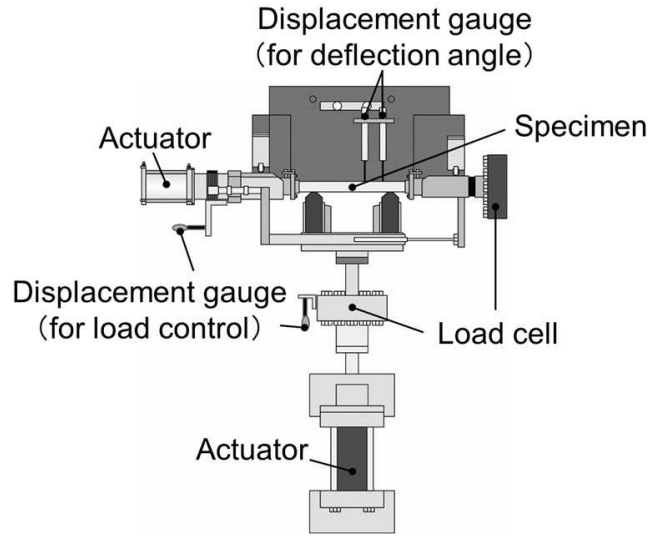

Fig. 6 Schematic diagram of the testing equipment for statically indeterminate fracture mechanics.

\subsection{Procedures}

The tests were carried out under the following five load conditions through the target point, $\sigma_{\mathrm{m}} / \sigma_{\mathrm{y}}$, on the theoretical plastic collapse limit curve (Fig. 2):

(1) concurrent loading (CL),

(2) tensile load followed by bending load (TB),

(3) bending load followed by tensile load (BT),

(4) pure tension (PT), and

(5) pure bending (PB).

The loading conditions of CL, TB, and BT were determined with $\sigma_{\mathrm{m}} / \sigma_{\mathrm{y}}=0.3,0.5$, and 0.7 as target points on the theoretical plastic collapse limit curve.

The stress-displacement diagrams and the stress-deflection diagrams were made and the plastic collapse stress was obtained from the load-displacement diagrams using the double elastic slope (DES) method (Saxena and Ramakrishnan, 
2006) (Suzuki et al., 2013). This method is used to evaluate the maintenance standards and is defined by the Japan Society of Mechanical Engineers. In this method, the intersection of a straight line having a slope $\xi$ twice the slope $\delta$ and the load-displacement diagram at the elastic limit is regarded as the plastic collapse point (Fig. 7). This method was applied to the membrane stress-axial displacement diagrams for the $0.7 \mathrm{CL}$ and $0.7 \mathrm{BT}$ tests, and to the bending stress-deflection angle diagram for the $0.7 \mathrm{~TB}$ test in this study. The experimental plastic collapse stress of a part-through notched specimen is compared with the theoretical plastic collapse stress and the experimental plastic collapse stress of a throughwall notched specimen.

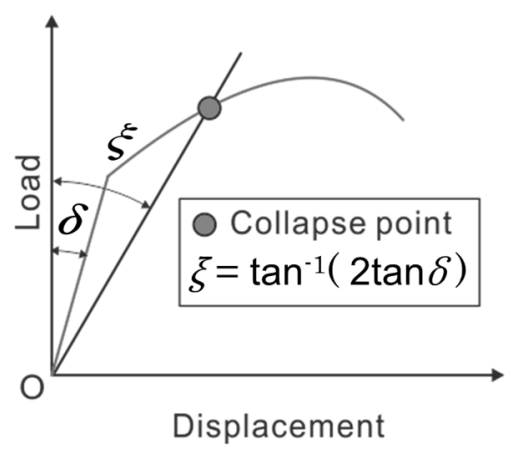

Fig. 7 Plastic collapse assessment method using the load versus displacement diagram.

The vertical and horizontal loads when the internal pressure began to decrease were used to calculate the membrane stress and bending stress at the crack penetration point. The crack penetration point was used to evaluate the validity of LBB. If the crack penetration stress occurs before the maximum stress, then the LBB is valid.

\section{Results and Discussion}

The actual loading paths are shown in Fig. 8. The arbitrary combined axial tensile and bending loads can be applied to the specimens through the target point using the developed test equipment. The internal pressure-time diagrams at the target point 0.7 and the loading paths for the CL, TB, and BT tests as typical pressure-time diagrams, are shown in Fig. 9. The abrupt lowering point of the internal pressure was observed for all testing conditions. The crack reached the inside of the pipe wall at the abrupt lowering point of the internal pressure. The internal pressure was slightly decreased before notch penetration because the internal volume of the specimen increased due to the loading test.

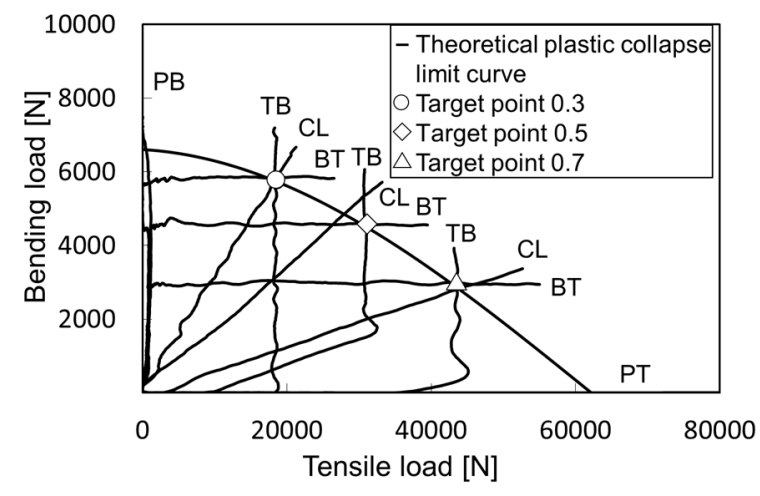

Fig. 8 Load paths of the part-through notched specimen.

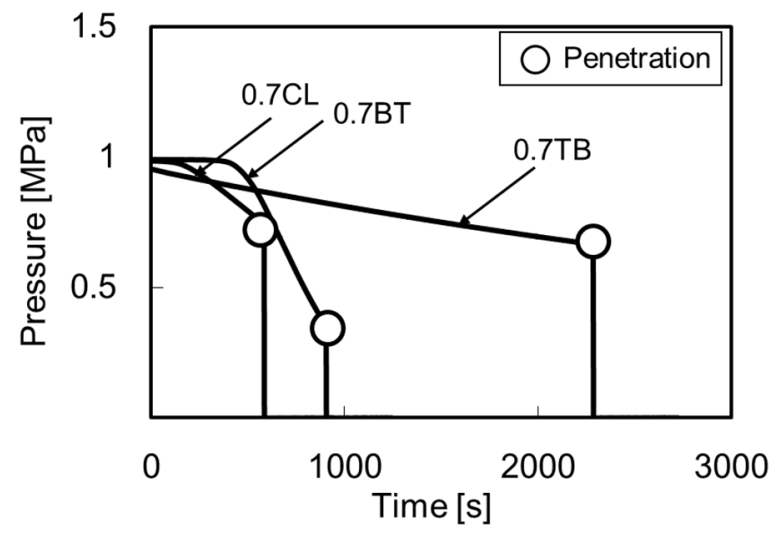

Fig. 9 Internal pressure-time curve. 
The membrane stress-axial displacement diagrams of the part-through notched specimen and the through-wall notched specimen for the $0.7 \mathrm{CL}$ and $0.7 \mathrm{BT}$ tests, as typical results, are shown in Figs. 10 and 11. The bending stress-deflection angle diagram for the $0.7 \mathrm{~TB}$ test is shown in Fig. 12, as a typical result. The plastic collapse strengths of the through-wall notched specimen and the part-through notched specimen are obtained from the above diagrams using the DES method. In Figs. 10, 11, and 12,,$\square$, and $\diamond$ indicate the plastic collapse points determined by the DES method, the crack penetration points, and the maximum stress points, respectively.

The plastic collapse strength of the part-through notched specimen was close to that of the through-wall notched specimen, and the average difference between the plastic collapse strengths was less than $10 \%$. The plastic collapse strength of the part-through notched specimen could be estimated using the plastic collapse strength of the through-wall notched specimen under all test conditions.

The membrane stress and bending stress of the part-through notched specimen decreased rapidly at the crack penetration point and increased for all loading conditions. Thus, LBB is valid under the combined tensile force and bending conditions considered in the present study because the crack penetration occurred in the stable fracture region.

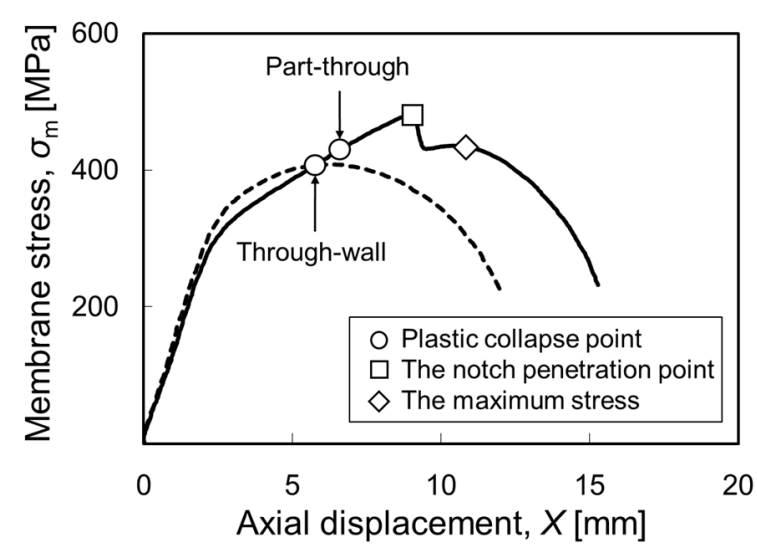

Fig. 10 Plastic collapse stress of through-wall and partthrough notched specimens in the CL test (target point: $0.7)$.

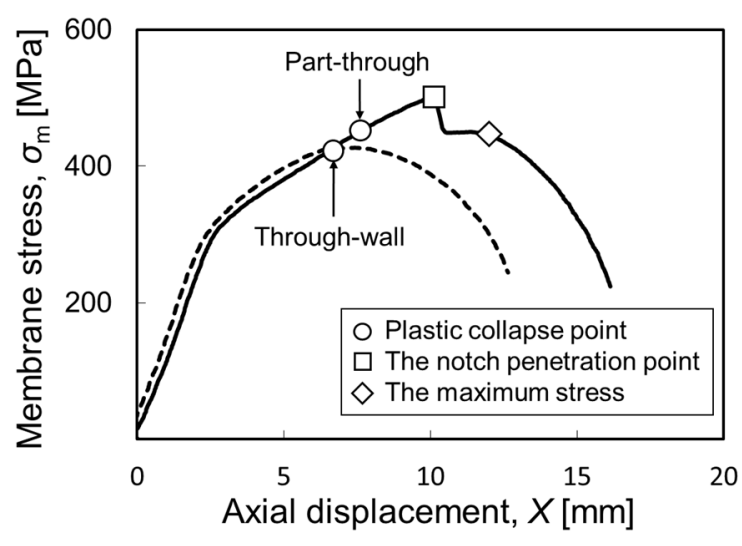

Fig. 11 Plastic collapse stress of through-wall and partthrough notched specimens in BT test (target point: 0.7).

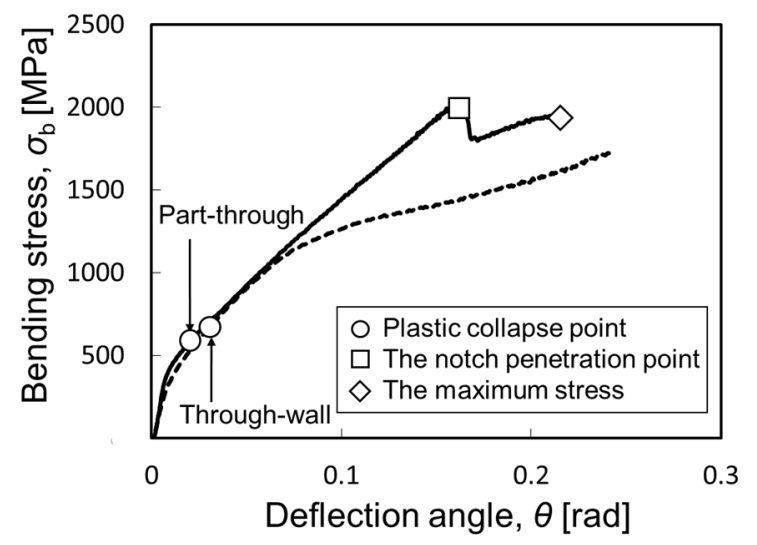

Fig. 12 Plastic collapse stress of through-wall and partthrough notched specimens in the TB test (target point: 0.7 ). 
The stress at the crack penetration point (penetration stress) of the part-through notched specimen is compared with the maximum stress after the crack penetration under each loading condition (Table 2). The following equation was used for calculation of the difference value $x$ :

$$
x=\frac{\left|\sigma_{P}-\sigma_{M}\right|}{\sigma_{P}}
$$

where $\sigma_{P}$ is the penetration stress and $\sigma_{M}$ is the maximum stress after the crack penetration under each loading condition.

The penetration stress is close to the maximum stress after crack penetration, and the difference between both stresses is less than $10 \%$ under most loading conditions. Therefore, the stress at the crack penetration point can be estimated using the same estimation formula of the maximum stress after crack penetration.

Table 2 Penetration stress and maximum stress after crack penetration of the part-through notched specimen.

\begin{tabular}{|c|c|c|c|}
\hline & $\begin{array}{c}\text { Penetration } \\
\text { stress, } \\
\sigma_{\mathrm{P}}[\mathrm{MPa}]\end{array}$ & $\begin{array}{c}\text { Maximum } \\
\text { stress, } \\
\sigma_{\mathrm{M}}[\mathrm{MPa}]\end{array}$ & $\begin{array}{c}\text { Difference, } \\
x[\%]\end{array}$ \\
\hline $0.3 \mathrm{CL}$ & 1831 & 1668 & 8.87 \\
\hline $0.5 \mathrm{CL}$ & 1115 & 1116 & 0.05 \\
\hline $0.7 \mathrm{CL}$ & 482 & 436 & 9.58 \\
\hline $0.3 \mathrm{BT}$ & 498 & 443 & 10.88 \\
\hline $0.5 \mathrm{BT}$ & 492 & 468 & 4.84 \\
\hline $0.7 \mathrm{BT}$ & 500 & 450 & 9.99 \\
\hline $0.3 \mathrm{~TB}$ & 1320 & 1234 & 6.52 \\
\hline $0.5 \mathrm{~TB}$ & 1457 & 1546 & 6.08 \\
\hline $0.7 \mathrm{~TB}$ & 1962 & 1948 & 0.81 \\
\hline PT & 501 & 475 & 5.06 \\
\hline PB & 877 & 749 & 11.55 \\
\hline
\end{tabular}

The penetration stress is estimated using the following estimation formula for the maximum stress:

$$
\begin{aligned}
& \sigma_{\mathrm{zm}}=1.9 \sigma_{\mathrm{y}}+\left(1-\sigma_{\mathrm{m}} / \sigma_{\mathrm{y}}\right) \sigma_{\mathrm{y}} \\
& \sigma_{\mathrm{zb}}=3.2 \sigma_{\mathrm{f}}-\left(1-\sigma_{\mathrm{m}} / \sigma_{\mathrm{y}}\right)\left(\sigma_{\mathrm{b}} / \sigma_{\mathrm{y}}\right) \sigma_{\mathrm{f}}
\end{aligned}
$$

where $\sigma_{\mathrm{f}}$ is the flow stress, which is the average of the yield stress and the tensile strength (Table 1). The value of 1.9 is the maximum value of membrane stress in the PT test and 3.2 is the maximum value of bending stress in the PB test. The evaluation curve is obtained by multiplying the horizontal axis component of the theoretical plastic collapse limit curve by $\sigma_{\mathrm{zm}}$ and the vertical axis component by $\sigma_{\mathrm{zb}}$. The evaluation curve is compared with the penetration stress and the maximum stress under each testing condition.

The penetration stress is plotted in Fig. 13, and theoretical plastic collapse limit curve and the evaluation curve of the part-through notched specimen are also plotted in Fig. 13. The penetration stress is larger than the theoretical plastic collapse stress. On the other hand, the penetration stresses are distributed approximately along the evaluation curve. Therefore, the penetration stress of the part-through notched specimen can be approximated using the estimation formula of the maximum stress under the loading conditions considered in the present study. 


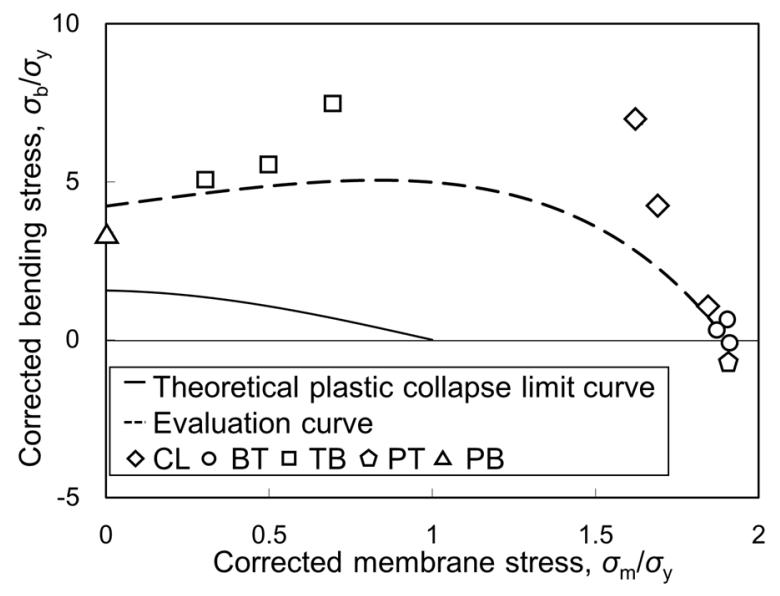

Fig. 13 Estimation for the penetration stress of part-through notched specimens.

The maximum stresses of the through-wall notched specimen and the part-through notched specimen are plotted in Fig. 14. The theoretical plastic collapse limit curve and the evaluation curve for the maximum stress of the part-through notched specimen are also shown in Fig. 14. The maximum stress of the part-through notched specimen is dispersed slightly outside that of the through-wall notched specimen under most loading conditions because the ligament area of the part-through notched specimen is larger than that of the through-wall notched specimen. On the other hand, both maximum stresses are dispersed approximately along the evaluation curve. Therefore, the maximum stress of the partthrough notched specimen can be approximated using the same estimation formula of the maximum stress under the loading conditions of the present study.

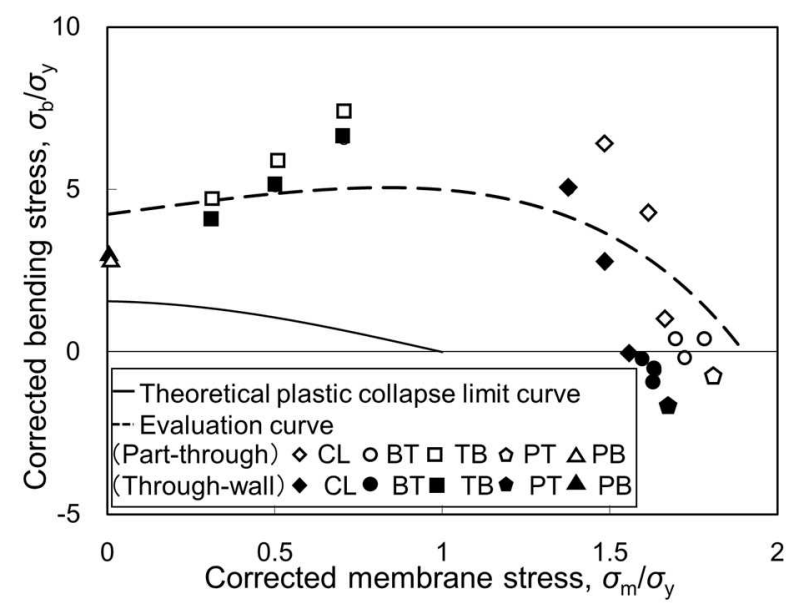

Fig. 14 Maximum stress estimation of through-wall notched specimens and part-through notched specimens.

\section{Conclusions}

In order to clarify the influence of load history on the validity of LBB for cracked austenitic stainless steel pipe subjected to a combined load of tension and bending, combined loading tests of axial force and bending were performed on stainless steel pipe with a single circumferential part-through notch with a notch angle of $90^{\circ}$ and a notch depth of $50 \%$ of wall thickness. As a result, the following conclusions were obtained. 
1) The LBB concept is valid for austenitic stainless steel pipe with a single circumferential part-through notch with a notch angle of $90^{\circ}$ and a notch depth of $50 \%$ of wall thickness under all loading conditions.

2) The penetration stress of the part-through notched specimen was approximately equal to the maximum stress after crack penetration and can be approximated using the estimation formula for the maximum stress.

3) The plastic collapse strength and the maximum stress of a part-through notched pipe can be approximated using the plastic collapse strength and maximum stress of a through-wall notched pipe having the same notch angle.

\section{References}

Izawa, S. and Matsubara, M., Plastic Collapse of a Notched Austenitic Stainless Steel Specimen Under Combined Tension and Bending (2007a), Transactions of the JSME, 73, 728, pp.537-543.

Izawa, S., Matsubara, M., Hirao, N., Busujima, K., Koyama, T., Machida. K., Kawada, D., Ohta, A. and Harizuka, H., Combined Tension-Bend System for Large Deformation Analysis (2007b), Experimental Techniques 31, pp.42-45.

Izawa, S., Matsubara, M., Nezu, K. and Sakamoto, K., Plastic Collapse Evaluation on the Notched Stainless Steel Piping Subjected to Combined Tension and Bending by Photo-Elastic Coating (2004), Key Engineering Materials (20012005), pp.270-273.

Matsubara, M., Izawa, S., Hirao, N., Busujima, K., Koyama, T., Machida, K., Kawada, D., Sakamoto, K. and Nezu, K., Development of a Testing Equipment for Studying Statically Indeterminate Fracture Mechanics (2003), Proceedings ICPVT-10, pp.481-486.

Okamura, H., Watanabe, K. and Takano, T., Deformation and Strength of Cracked Member under Bending Moment and Axial Force (1975), Engineering Fracture Mechanics 7, pp.531-539.

Saxena, S. and Ramakrishnan, N., Characterization of plastic collapse load determination in circumferentially throughwall cracked elbows (2006), Nuclear Engineering and Design 236, pp.1739-1747.

Suzuki, R., Matsubara, M., Sakamoto, K., Suzuki, M., Shiraishi, T., Yanagihara, S., Izawa, S., and Wakai, T., Observation and Evaluation of Plastic Collapse for Double-Notch Pipe (2013), Experimental Techniques, (Online published).

Suzuki, R., Matsubara, M., Yanagihara, S., Morijiri, M., Omori, A. and Wakai, T., Collapse evaluation of double notched stainless pipes subjected to combined tension and bending (2016), Procedia Materials Science 12, pp.24-29.

The Japan Society of Mechanical Engineers, Rules on Protection Design against Postulated Pipe Rupture for Nuclear Power Plants (2002), JSME S ND 1-2002.

The Japan Society of Mechanical Engineers, Rules on Fitness-for-Service for Nuclear Power Plants (2008), JSME S NA $1-2008$. 